\title{
Providing Meaningful Interactions at KOSEN between Japanese and International Students
}

\author{
Richard Grumbine*1, Natsuki Aka ${ }^{1}$ and Riho Hirano ${ }^{1}$ \\ ${ }^{1}$ National Institute of Technology - Ariake College, Japan
}

\begin{abstract}
Internationalizing the Japanese students at KOSEN has proven difficult. While KOSEN welcomes international students with the hope of internationalizing the almost entirely Japanese student body, the challenge has been to get the Japanese students to interact with the international students and take advantage of the opportunity. Far too often international students live in a bubble and have meaningful contact with only a few students. This leaves the international students feeling isolated and the Japanese students not benefiting from the opportunity that KOSEN is trying to provide. Ariake KOSEN attempted to address this problem in two ways. A discussion class which included international students was created where the students were expected to discuss pre-assigned topics in small groups over the course of a semester. These groups often contained an international student. This forced exposure created a chance for Japanese students to communicate with international students. This communication was then seen continuing well beyond the discussion exercises. A survey was given at the completion of the one semester class to evaluate effectiveness. The results show that students found the opportunity to be helpful and in line with their own learning goals. Another approach was to create a more casual place for students to gather and interact with international students. An English Lab was created to give the students a place to interact outside of the traditional classroom atmosphere. This second effort is just in the beginning stages but the basic ideas are laid out in this paper. Anecdotal evidence seems to suggest that the Lab is working, with usage on the part of Japanese students being high, but the international students seem less inclined to use the room.
\end{abstract}

\section{Introduction}

The KOSEN system (Japanese National Institutes of Technology) is attempting to better internationalize and create more globally minded engineers. In fact, this is the third of three educational purposes espoused by KOSEN in their latest promotional literature, "To develop practical engineers equipped with a high professional ethics, a wide view, and international mind [sic]" (NIT-A School Catalog, 2017). To this end, KOSEN invite international students

\footnotetext{
${ }^{1}$ Corresponding author: richard@ariake-nct.ac.jp
} 
to study at their campuses and make available many internships and exchange programs to both bring international students to KOSEN and give KOSEN students opportunities to travel abroad. Many of these students receive scholarships or other financial aid from the Japanese government to help in these internationalizing efforts, for example JASSO funds many such programs (JASSO, 2017). However, even with these programs and efforts in place, Ariake KOSEN usually only has about 5 full time international students and a small number of international interns who have much shorter stays. One of the reasons these international students are admitted is because of the need to internationalize the mostly Japanese student body and to help students build a more global mindset. But it was observed that the international and Japanese students did not interact very often. A survey was given to assess the reasons why Japanese students did not take advantage of the opportunity to interact with the international students (Hirano, 2018). No survey has as yet been given to the international students but is under consideration; however, the number of international students is so small as to likely yield statistically insignificant results. Concurrently to the giving of this survey two different English teachers tried two very different approaches to encourage greater interaction between the Japanese students and international students. One author created a discussion class featuring several international students and another author created an English Lab to encourage a more informal interaction between international students and Japanese students. Each will be discussed in turn.

\subsection{Discussion Class}

\subsubsection{Introduction}

In order to address the issue of international interaction, a selective discussion class was created including three international students. The class was made up of twenty-four Japanese fourth year KOSEN students (similar to freshman university engineering students) plus three international students. The Japanese students were divided into five groups according to their own preferences. Two groups contained a single international student while the other two groups shared an international student between them. The class met once a week with discussion topics pre-assigned. Before class the students were required to write a four-paragraph essay on the upcoming topic to help the students form opinions and to help them feel more comfortable during discussions. About 20 minutes of discussion time was allocated per meeting. An English teacher was also available to help facilitate the discussions and there were two TAs who helped the students write their essays, one a native Japanese but fluent in English and one an international student also fluent in English (both TAs had a similar class the year before with the same teacher giving them familiarity with the classroom mechanics).

\subsubsection{Evaluation Survey}

A five-question survey was given to the students at the end of the semester. The questions and results can be found below. Students seemed to enjoy taking the discussion class, since none answered they did not enjoy the class (Figure 1). As the discussion class was a selective class, most of the students took it to improve their English ability (Figure 2). The interesting point that was revealed by the survey was that while about $65 \%$ of the students found the class difficult or very difficult, and no one responded that the class was easy (Figure 3), they still felt that they would want to take a similar class again in the future (Figure 4). They also 
mentioned that the skills they would most like to improve in English are listening and speaking skills (Figure 5).

Q1. Did you enjoy the class?

Q2. Why did you take this class?

Q3. How difficult was the class?

Q4. Do you want to take a similar speaking and writing class again?

Q5. What skills do you want to improve?

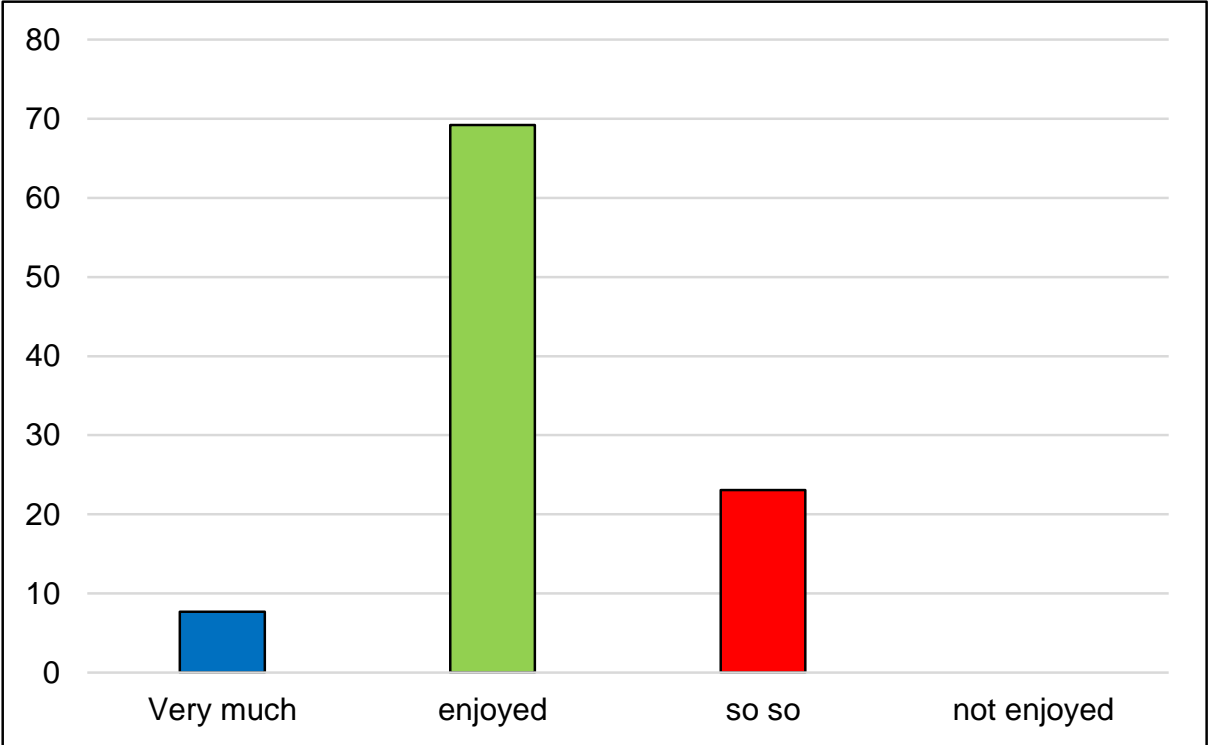

Fig. 1. The result of Q1: Did you enjoy the class?

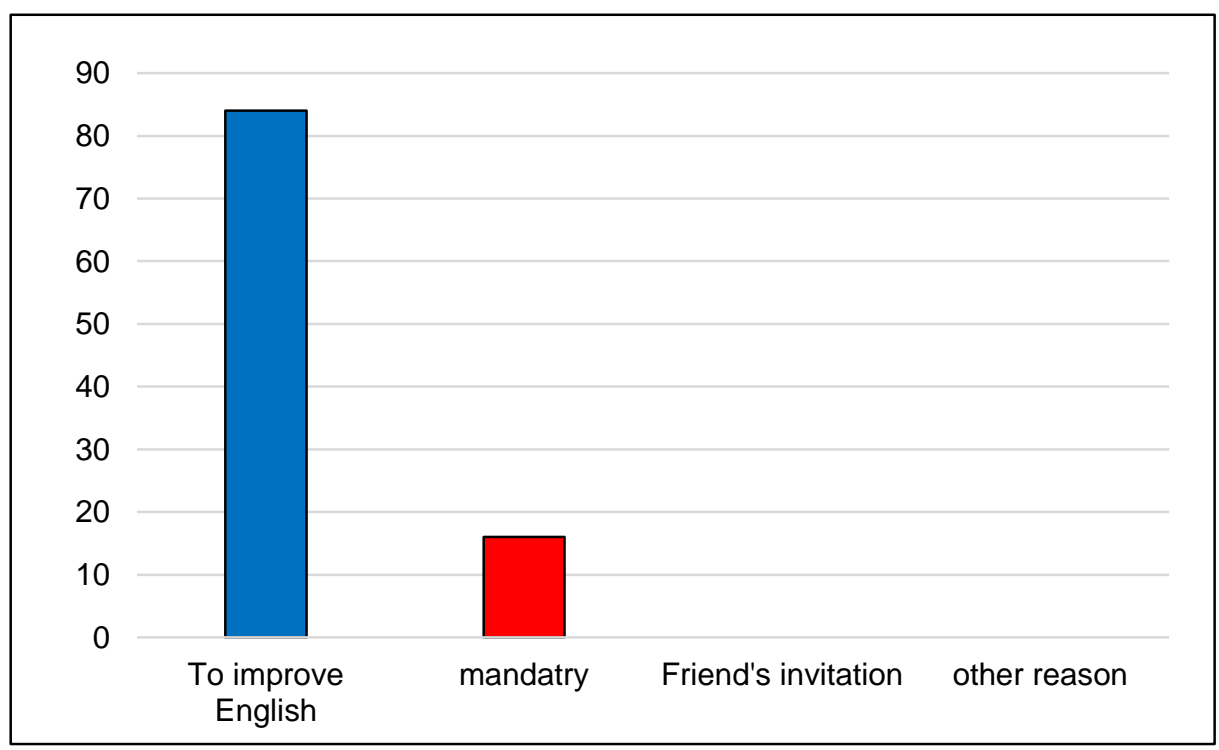

Fig. 2. The result of Q2: Why did you take this class? 


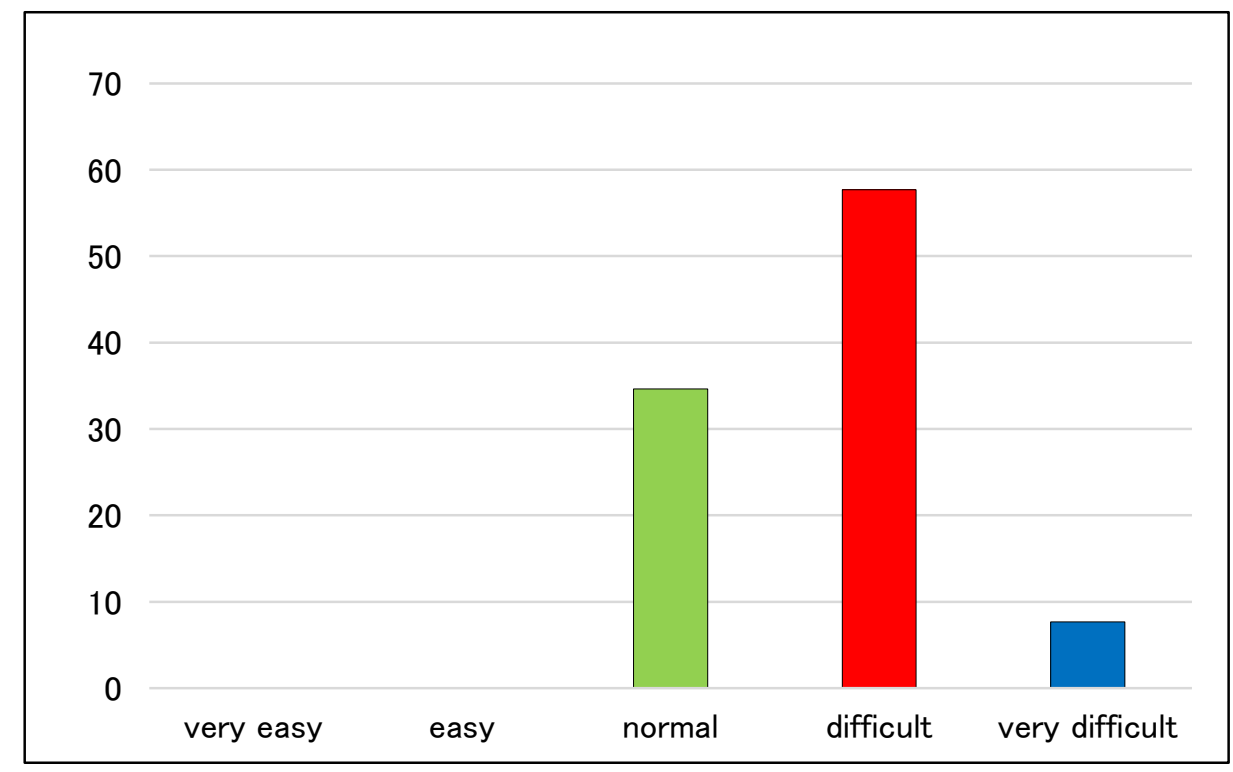

Fig. 3. The result of Q3: How was the class?

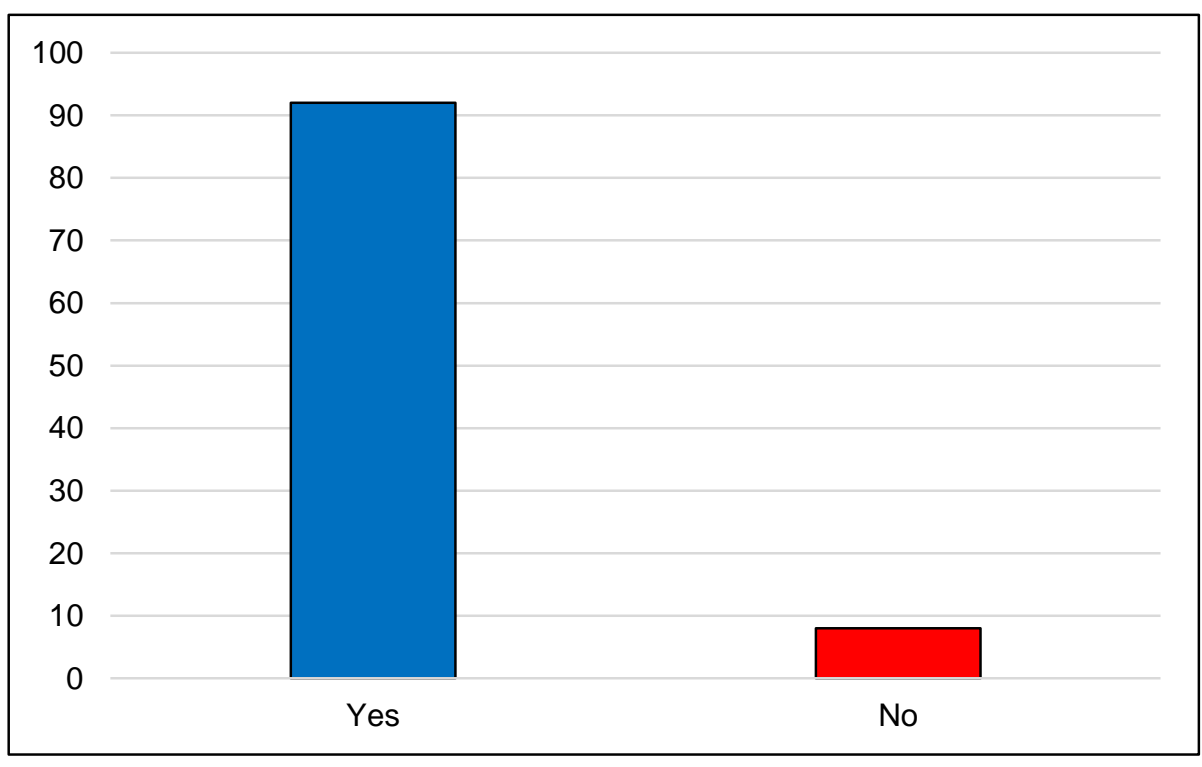

Fig. 4. The result of Q4: Do you want to take a similar speaking and writing class again? 


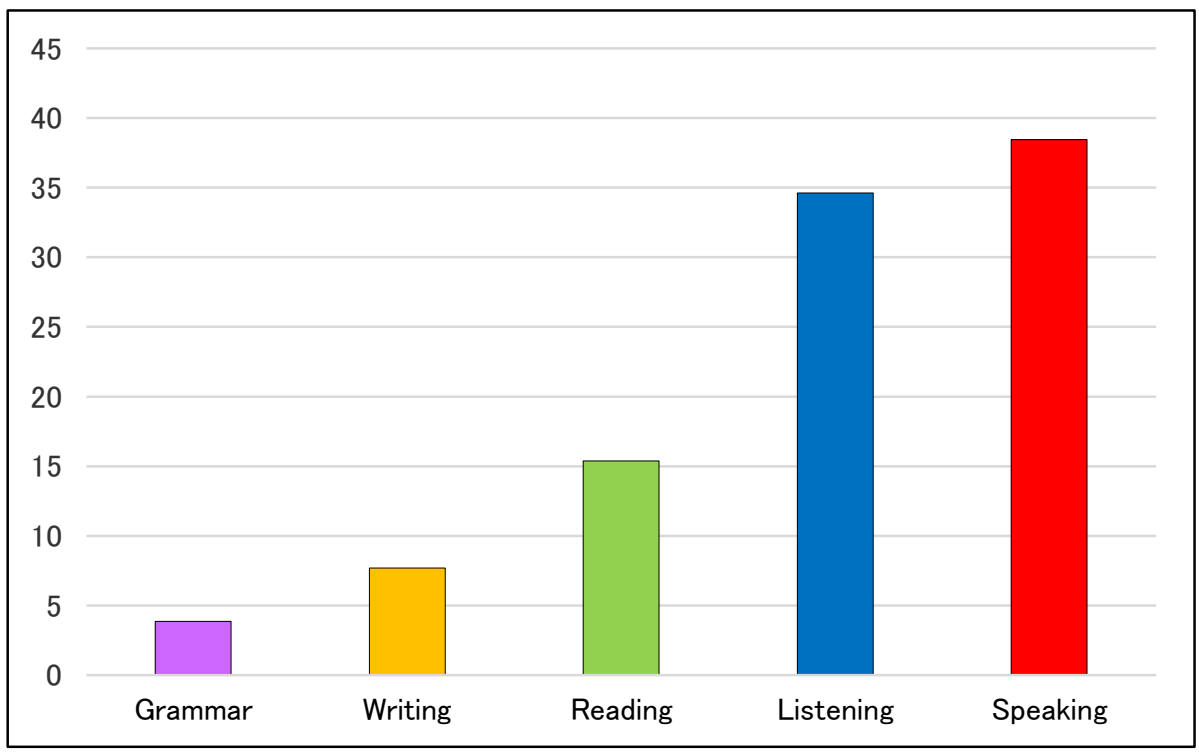

Fig 5. The result of Q5: What skills do you want to improve?

A follow up question was then asked, what had they learned in class. Below are the responses from students.

1. Even though I do not use difficult English words, and cannot speak fluently, I can convey what I want to say in English.

2. If I cannot understand what other speakers say, it is difficult for me to speak. I need to improve listening skills.

3. I could convey the message by using simple grammar.

4. It was a practice not only for speaking development, but also it enhanced my listening skills.

5. The important thing is to have my ideas first. If we do not know what to say in Japanese, then, we cannot express the thoughts in English.

6. I learned how to write an essay in English.

7. I found that if we take time, we can improve speaking skills. The class was beneficial for me and I found if I could speak more English, it would have been more interesting.

\subsubsection{Discussion of results}

According to the questionnaire, most of the students enjoyed the discussion class. One reason may be that the class was selective, therefore, mostly already motivated learners joined this class. Though the students felt it was challenging to prepare for writing and expressing their ideas in English, they said they would want to try this kind of class again. This is a good indication that they have learned something they feel is important through the discussion class. The most important point is they could have a chance to communicate in English. Japanese students tend to be very shy, always caring about mistakes (Saito and Eisenstein 2004). They feel making mistakes in front of other people is not good. English teachers need to address such self-imposed stereo-types concerning Japanese students. Conversation practice in small groups may help students to feel less pressure about making mistakes while 
talking to others in English. Such training will also help them realize that with simple English they can convey their message. The data also shows students hope to improve their speaking and listening ability, indicating they felt they want to improve these English skills even more after experiencing the discussion class.

The authors observed that groups with international students spoke in English more often and with more fluency than groups that did not contain an international student. Also, having an international student in the group allowed the students to explore issues of international differences. Discussions in these groups were also often seen continuing outside of class as well. These last two points show that this attempt to internationalize the Japanese students was somewhat successful. Students learned about foreign cultures and spent time talking with foreign students. But further research is needed to investigate this more thoroughly.

\subsection{English Lab}

\subsubsection{Introduction}

The English Lab was created with three purposes in mind. First and foremost, to help students with their English skills, especially conversational English and presentation skills. Secondly the LAB is meant to help faculty and staff with their English needs, primarily editing of academic papers and emails, and helping with academic presentations. And thirdly and pertinent to the issue at hand, internationalizing the students and giving them a chance to interact with people from other countries/cultures in a non-classroom setting. This last point was felt to be important by the authors as student anxiety in the classroom sometimes hinders learning (Horwitz, E., Horwitz, M., Cope J. 1986).

Although most KOSEN accept international students and perhaps employ a few international teachers (Ariake Kosen has roughly 1000 students and 80 faculty members, with five international students and three international faculty members from abroad), the Japanese students reported having difficulty interacting with the foreign students. A survey identified four areas of concern on the part of the Japanese students as reasons for not interacting with foreign students: shyness, lack of confidence, few chances for interaction, and difficulty finding a reason or topic for conversation (Hirano, 2018). The English Lab it was hoped could help address these concerns. The English Lab was envisioned to be a place where the international students could relax and interact with the Japanese students in a more casual atmosphere. (The school itself provides little in the way of community or common spaces on campus). The lab is small (seats about twelve people comfortably - three on a couch, and eight around a conference table plus one more chair) and is business casual in atmosphere (the donor room was a conference room and it still has to serve that purpose when helping students, faculty, and staff with presentations). Basic amenities to facilitate casual interaction and to provide a more relaxed atmosphere are provided by the Lab. These include: comfortable chairs, conference style table, quality audio and video systems, coffee and tea pots, a microwave, selection of books and magazines, phone charging station, a video game system, and a computer with internet access. It is hoped that by creating this space the students would find it an encouraging place to intact with one another. The lab was just completed at the end of last semester and this is the beginning of its first full semester of usage so little can be said about its effectiveness at present. Three weeks into the new school year, has seen the lab have regular attendance from many first-year students. About fifteen visitors per day (the lab is open four days a week, two hours after school Wednesday and Friday, and one hour at lunch time Tuesday and Thursday - so hours are quite limited). Most 
of the visitors are new students, though a few upper level students also come regularly. Only one intentional student currently comes with regularity. In the future, a paid system of attendance for international students may be tried to both encourage them to come to the room and to expand the hours of the Lab. A survey is also planned to ask students how they want to use the room and what amenities they would like to see provided, so that we can make it even more user friendly.

\subsubsection{Challenges}

There have been several challenges in creating, maintaining, and improving the lab. Acquiring a suitable space and enough funding for creating the lab were the first hurdles. In this case timing was good, as a semi suitable room became available, setting the stage for obtaining funding. A presentation was given to the school president, in order to obtain funds directly from the school (there was not enough time to pursue outside funding). In the end were given half of the monies we felt were required. This led to some cuts in amenities and a search for some outside funding sources in the future. Also, several English teachers donated some of their research funds to the project and or items that were needed. In all, about 500,000 yen was spent, with a few also items being donated. Once the lab was about to be up and running there were several other challenges that had to be dealt with. How would we get students to come to the lab? And how to get them to interact once they were there? Giving the lab an eye-catching exterior helped it capture attention (bright yellow vinyl wrap with the new room's name in big bold letters). Offering free coffee and tea also helped get students to explore the space and stay long enough to talk with one another and with the host (an American teacher at the school). On the down side, the international students this year have been off to a rough start due to some immigration issues beyond our control. So, no formal introduction for the three new incoming students this year has as yet been made to our students. And only one of the new international students has been to the lab so far. A returning international student however has been coming weekly and plans to come more often. Perhaps another problem is that this year most of the new international students do not speak much English and prefer Japanese, so the English aspect of the lab may be working against one of its purposes in some ways. This is a first-time issue, so not sure if it will be a continuing trend with future incoming students. A final challenge is staffing and paying for consumables because there is no current monetary allotment for these two things. The lab's only staff is also a full-time teacher at the school with most of the usual responsibilities of a full teaching load so there is not so much time for working in the lab, hence its rather short hours (the lab is currently only open six hours a week). Also, all monies for consumables comes out of that teacher's pocket at present. To address these last two issues, it is hoped that we can get the school to recognize the Lab as an official school committee or service and let its supervision take the place of other committee and service work on the teacher's part and find ways of getting some minimal funding for consumables.

\subsubsection{Evaluation}

The lab has so far only been partially successful in achieving its goals. While it has been heavily used by Japanese students and faculty members, there have been precious few visits by foreign students. The most recent TOEIC scores show that Japanese students who use the lab regularly scored very well. With five of the top ten scores being achieved by English Lab regulars and all five having shown great improvement in their scores over a short period of time (at least 100 points in a single semester). Likewise, faculty and staff usage of the lab's 
editing services has been quite frequent with at least one visitor per week. But precious few visits are made by the international students at the school. In fact, they only seem to occur about once every few weeks.

A survey given to regular Japanese attendees of the English Lab showed that $60 \%$ of the students would appreciate talking with foreign students in the lab and no students indicated that they would not like to interact with foreign students, so increasing foreign student attendance is a priority.

\section{Closing remarks}

These two attempts to internationalize the student body (integrated discussion class and English Lab) have been moderately successful but there is still plenty of room for improvement. It would be very helpful if the number of international students in the discussion class could be increased so that there was one international student per group. And in a similar vein, the English Lab needs better attendance by international students and more flexible hours so that it can be more available to Japanese students. The general lack of international students on campus makes solving these issues very difficult. The number at our KOSEN has been fixed at about five international students total in the student body. This number has remained unchanged for at least fifteen years. This is despite an upward trend (better than 10\% increase year on year for the last three years) of international students enrolled in Japanese universities in general (JASSO, 2017). However, these numbers do not take into account the many temporary students visiting our KOSEN from abroad, and those numbers have been increasing over the last several years (12 in 2014, 16 in 2015, 18 in 2016 and 17, and at least 20 are expected this year). Although it is hard to integrate these temporary visitors into a discussion class it is easy to incorporate them into activities in the English Lab.

\section{Suggestions}

So how to improve the overall situation at KOSEN? Both of the afore mentioned attempts to improve globalization could benefit from greater numbers of international students being enrolled full-time at KOSEN. And in the case of the English Lab some small amount of funding to pay existing international students a stipend to attend the lab making the lab more available for use (from six hours now to perhaps twelve hours a week or so with additional hours being staffed by international students). Increasing the numbers of international students and the opportunities for interaction would only improve the chances of these programs having greater success.

\section{Further research and other concerns}

The issue of increasing international student enrollment will quite likely lead to another issue, how to adequately serve those international students. Anecdotal evidence seems to suggest that at least for Ariake, the environment is not too attractive for most international students. Also, the limited number of international students at the school makes meaningful research difficult as it is hard to expect any statistically significant results from such small numbers, so anecdotal evidence is about the best we can expect. 


\section{References}

Hirano, Riho (2018) Taking advantage of international students, Japan Counsel of College English Teachers, National Presentation Contest

Horwitz, E., Horwitz, M., Cope J. (1986) Foreign language classroom anxiety. Modern Language Journal, 70(2), 125-132.

JASSO 2017 (2017) International students in Japan 2017 retrieved from https://www.jasso.go.jp/en/about/statistics/intl_student/data2017.html

NITA School Catalog 2017 (2017) National Institute of Technology, Ariake College

Saito H., Eisenstein M. (2004) Seeing English language teaching and learning through the eyes of Japanese EFL and ESL students. Foreign Language Annals, 37(1), 111-124

Schweers, C. W. (1999) Using L1 in the L2 classroom. English Teaching Forum, 37(2), 615. 